\title{
The relationship between resilience and parenting burden among mothers of children with disability; The mediating effect of the health perception
}

\author{
Hye-Young Kim¹)
}

\begin{abstract}
The purpose of this descriptive survey study was to identify the mediating effects of health perception between resilience and parenting burden among mothers of children with developmental disabilities. The health of children with developmental disabilities are dependent on their mothers' health. Subjects of the study were 108 mothers who have 3-9 years old children diagnosed with developmental disabilities. Self-report questionnaires were used to collect data. Data were analyzed with descriptive statistics, Pearson's correlation coefficient, and three-step mediated regression analysis using SPSS/WIN 22.0 programs. Mother's health perception had partial mediating effects in the relationship between resilience and parenting burden with explanatory power of $38 \%$ (Sobel test: $Z=6.32, p<.001$ ). This indicates that resilience not only has a significant effect on parenting burden, but also health perception has a significant effect on parenting burden. Therefore, to reduce the parenting burden of mothers with disabilities, it is reported that supportive forms and interviews that are not tied to formalism are effective in reducing parenting burden through the improvement of mothers' resilience.
\end{abstract}

Keywords : Resilience, Parenting burden, Health perception, Mediating effect, Developmental disability

\section{Introduction}

Most children with developmental disabilities have a lack of daily living skills, interpersonal relationships, therefore it is important that parents take care of them[1]. If a child has a health problem, the relationship between mothers and children will continue to influence each other[2]. Mothers of children with developmental disabilities are more likely to have difficulty in parenting their children grows as the physical and emotional demands change. In particular, mothers are threatened with their health[3].

Health of parents are important for the development of children as well as for normal

Received(June 8, 2018), Review Result(1st: June 14, 2018, 2nd: June 22, 2018), Accepted(June 26, 2018)

${ }^{1}$ College of Nursing, Keimyung Univ., 1095 Dalgubeoul-daero, Dalseo-gu, Daegu, Korea

email: hye11533@kmu.ac.kr 
children. Health and parenting stress of mothers affect on quality of care for child[1]. Parents are likely to experience parenting burden because of the need for long-term care along with the growth of the child, and the resilience works to cope with this. The resilience is the ability of the victims who are in crisis or stress to exhibit psychological and emotional problems and lack of resilience[2][4]. The resilience is understood as a power to adapt and cope with change and adversity while being applied to people, and to adapt positively even in difficulties[5].

According to a study of parents with children with chronic mental and physical disabilities, the greatest personal and social need for children with disabilities is related to the health of them and their child[1]. However, in Korea, as various welfare policies and institutional support for children with disabilities are insufficient, the health problem for mothers with disabilities is often transferred to the responsibility of the family[4][6]. The care of a child is mainly carried out in the care of the family in everyday life. Especially, the role of the mother is very burdensome. For example, she should move to the treatment institution with her child and care at home together all day. Mothers spend a lot of time with their children, so they can tired and do not have time to care for their health[7].

The health of children with developmental disabilities are dependent on their mothers. In order for the child to be given health care, it is necessary for the mothers to feel less stress of care and to maintain good health condition[8]. This study aimed to identify the mediating effects of health perception between resilience and parenting burden among mothers of children with developmental disabilities.

\section{Methods}

\subsection{Design}

A cross-sectional survey was employed to identify the mediating effects of health perception between resilience and parenting burden among mothers of children with developmental disabilities.

\subsection{Participants}

The subjects consisted of 108 mothers who regularly visit the welfare center for their child with developmental disabilities. The welfare center is located in Andong city in Korea. The criterion of participation is the mother who has 3-9 years old child diagnosed with 
developmental disorder. The number of subjects was calculated using the G*Power program 3.1.9.2 version, the effect size was set at .15, significance level .05, and statistical power of .80 . The sample size required for regression analysis was calculated to be 98 , but 130 copies were distributed considering the dropout. A total of 108 participants's data were used for analysis except for 22 fraudulent responses.

\subsection{Instrument}

2.3.1. Health perception: The health perception was measured by a tool modified and supplemented by Lee[9] developed by The Ware Perception Questionnaire developed by Ware [10]. This tool is composed of 20 questions, 7 items of current health, 2 items of past health, 2 items of future health, 4 items of health concern, 2 items of resistance and sensitivity, and 3 items of rejection of patient role. 4-point Likert scale. The higher the score, the higher the subjective health status. Cronbach's a was .72 at the time of development of this tool, and Cronbach's a was .72 in Lee[9]. In this study, Cronbach's a was .83.

2.3.2. Resilience: In this study, instrument developed by Wagnild and Young[11] that translated into Korean by Song[12] was used. That consisted of 25 items, composed of 17 items on the competence of the individual and 8 items on the acceptance of his/her life were tools that Song[12]. This instrument is a 7 point scale from 1 point to 7 points. The higher the score, the higher the overcoming power. The possible score is from 25 to 175 points. The reliability of the instrument at the time of development was Cronbach's alpha $=.85$ and the reliability of the study was Cronbach's alpha $=.93$.

2.3.3. Parenting burden: parenting burden was measured using the Korean version of Parenting Stress Index - Short Form developed by Abidin[13] and standardized by Lee et al. [14]. This tool is divided into three sub - domains of parenting, parent - child relationship, and childhood, and consists of 36 questions, 12 questions for each area. A 5-point Likert scale consisting of 5 points from 'not at all' to 'highly agree' means higher parenting burden. Cronbach's a was .91 at the time of development of this tool, and Cronbach's a was .91 in study of Lee et al[14]. In this study, Cronbach's a was .90. 


\subsection{Data analysis}

Data analysis was conducted using IBM SPSS version 23.0. General characteristics of the subjects, health perception, resilience, and parenting burden were analyzed by frequency analysis and descriptive statistics. The correlations between the subjects' health perception, resilience, and parenting burden were analyzed by Pearson correlation coefficient. Three-step mediated regression analysis by Baron and Kenny[15] was conducted to examine the mediating effects of health perceptions on the relationship between resilience and parenting burden. Statistical significance was verified by Sobel test.

\section{Results}

\subsection{General characteristics}

The general characteristics of the study subjects are as follows (table 1). The mean age of the subjects was $37.64 \pm 5.33$. Most of the subjects' education level was over high school.

[Table 1] General characteristics of the subjects $(\mathrm{N}=108)$

\begin{tabular}{|c|c|c|}
\hline Variables & Category & $\mathrm{n}(\%)$ or Mean \pm SD \\
\hline Age(yr) & & $37.64 \pm 5.33$ \\
\hline Education level & Middle school & $8(7.41)$ \\
& High school & $49(45.37)$ \\
& College & $51(47.22)$ \\
\hline Birth order & 1st & $6(5.56)$ \\
& 2nd & $44(40.74)$ \\
& 3rd & $58(53.70)$ \\
\hline Age of child(yr) & $3-5$ & $80(74.07)$ \\
& $6-9$ & $28(25.93)$ \\
\hline
\end{tabular}

3.2 Level of health perception, resilience and parenting burden

The scores of health perception, resilience, and parenting burden measured in this study are shown in Table 2. 
[Table 2] Health perception, resilience and parenting burden $(\mathrm{N}=108)$

\begin{tabular}{|c|c|c|c|}
\hline Variables & Min & Max & Mean \pm SD \\
\hline Health perception & 1 & 4 & $2.36 \pm 0.25$ \\
\hline Resilience & 1 & 7 & $4.80 \pm 0.71$ \\
\hline Parenting burden & 1 & 5 & $3.43 \pm 0.44$ \\
\hline
\end{tabular}

\subsection{Correlation among health perception, resilience and parenting burden}

The relationship between health perception and resilience showed positively correlated ( $\mathrm{r}=$ $.41, \mathrm{p}$ <.001). The relationship between health perception and parenting burden showed negatively correlated $(\mathrm{r}=-.44, \mathrm{p}<.001)$. There was a significant negative correlation $(\mathrm{r}=-.33, \mathrm{p}$ $<.001$ ) between resilience and parenting burden (Table 3).

[Table 3] Correlation among health perception, resilience and parenting burden ( $N=108)$

\begin{tabular}{|c|c|c|c|}
\hline \multirow{2}{*}{ Variables } & Health perception & Resilience & Parenting burden \\
\cline { 2 - 4 } & $\mathrm{r}(\mathrm{p})$ & $\mathrm{r}(\mathrm{p})$ & $\mathrm{r}(\mathrm{p})$ \\
\hline Health perception & 1 & & \\
\hline Resilience & $.41(<.001)$ & 1 & 1 \\
\hline parenting burden & $-.44(<.001)$ & $-.33(<.001)$ & \\
\hline
\end{tabular}

3.4 The mediating effects of health status between resilience and parenting burden

Before examining the mediating effect, we examined the multi-collinearity between dependent variables, parenting burden and independent variables. As a result, the Durbinwaston index was 1.69, close to 2 and appeared independently. The multi-collinearity showed that the Variance Inflation Factor (VIF) index was less than 10 because the index was less than 10. Therefore, this data is suitable for regression analysis. The results of the regression analysis according to the three - step procedure are as follows Table 4. As a result of the Sobel test, the health perception had a significant partial mediating effect on the relationship between resilience and parenting burden $(Z=5.89, \mathrm{p}<.001)$. 
The relationship between resilience and parenting burden; The mediating effect of the health perception

[Table 4] Mediating effect of health perception on the relationship between resilience and parenting burden $(\mathrm{N}=108)$

\begin{tabular}{|c|c|c|c|c|c|c|}
\hline Steps & $\beta$ & $\mathrm{t}$ & $\mathrm{p}$ & Adj. $R^{2}$ & $\mathrm{~F}$ & $\mathrm{P}$ \\
\hline Step 1. Resilience - health perception & .41 & 7.22 & $<.001$ & .30 & 37.50 & $<.001$ \\
\hline Step 2 Resilience - parenting burden & -.32 & 5.72 & $<.001$ & .24 & 18.34 & $<.001$ \\
\hline $\begin{array}{l}\text { Step } 3 \text { Resilience - parenting burden } \\
\text { Health perception - parenting burden }\end{array}$ & $\begin{array}{l}-.17 \\
-.44\end{array}$ & $\begin{array}{l}1.91 \\
6.02\end{array}$ & $\begin{array}{l}.028 \\
<.001\end{array}$ & .38 & 32.91 & $<.001$ \\
\hline
\end{tabular}

Sobel test: $Z=6.32, \quad p<.001$

\section{Discussion}

This is a study on resilience, parenting burden, and health perceptions of mothers of children with disabilities. Because the mother's problem, which is the primary care provider for the child with disabilities, affects all the family members, the mediating effect of health perceptions on the resilience and parenting burden correlation experienced by them is tried to be confirmed.

In this study, the subjects' resilience and health perception had a negative relationship with parenting burden. This suggests that improving the coping ability and improving the health of the subject can reduce the stress of the parenting. Particularly, health perception has a partial mediating effect. This indicates that resilience not only has a significant effect on parenting burden, but also health perception has a significant effect on parenting burden.

In order to reduce the parenting burden of mothers with disabilities, it is reported that supportive forms and interviews that are not tied to formalism are effective in reducing parenting burden through the improvement of mothers' resilience[16]. In addition, a study of mothers of children with autism attempted to reduce parenting stress through information on parenting methods and information. Some support programs for mothers of children with disabilities have been developed and applied, but in fact their health problem has not been considered[17][18].

The most important factor affecting the development of children with developmental disabilities is how active parents are caring for children's health[19]. However, most of the mothers of children with developmental disabilities in Korea are burdened not only with housework but also with children with disabilities, so the physical and psychological difficulties of mothers are increasing[19][20]. Therefore, in order to help mothers with the children with developmental disabilities, various forms of support programs should be developed to help 
mother maintain the resilience and healthy state[21]. In particular, the development of nursing intervention programs for the health of mother with developmental disability children and their families should be studied continuously and practical support should be made available for use in the community.

\section{Conclusion}

This study is a descriptive research study that confirms the mediating effect of health perception on the coping power of mother with developmental disability and parenting burden relationship. The results showed that coping power, parenting burden, and health perception were statistically significant. In the regression analysis with mediating effects, the perceived health of the subjects showed a power of $38 \%$ in the relationship between coping power and parenting burden. In other words, this study confirmed the importance of mothers' health for caring for children with developmental disabilities and suggested that effective intervention should be developed for mothers with developmental disabilities.

\section{References}

[1] H. Y. Kim. The Effect of the Health Education Program for Mothers with Developmental Disabled Children on Health Care Behavior and Parenting Stress, Journal of the Korea Academia-Industrial cooperation Society (2016), Vol.17, No.6, pp.338-346.

[2] J. H. Kim and M. K. Jin, The Mediating Effects of Psychological Well-being on the Relationship between Parenting Stress and Parenting Behavior of Mothers of Children with Developmental Disabilities, Korean Journal of Play Therapy (2015), Vol.18, No.4, pp.285-305.

[3] H. J. Shin, The Meaning of Nurturing Experience of Developmental Disorder Children's Mother, Family and Culture (2014), Vol.26, No.2, 80-125.

[4] S. Y. Ahn, The Effects of the Parenting Stress, Depression and Disability Acceptance of Developmental Disability Children's Mothers have on Child Abuse, Korean Council of Physical, Multiple \& Health Disabilities (2015), Vol.58, No.1, 219-238.

[5] J. M. Levy, AAMR Promoting Family Health and Resilience: AAMR Promotes Progressive Policies, Sound Research, Effective Practices, and Universal Human Rights for People with Intellectual Disabilities, Exceptional Parent (2003), Vol.33, No.2, pp.54-57.

[6] S. W. Han, The Structural Relationship Among Caregiving Self-Efficacy, Parental Stress and Maternal Sensitivity in Mothers of Children with Developmental Disabilities, Korean Journal of Family Welfare 
(2011), Vol.16, No.2, pp.145-161.

[7] K. Y. Kim, Medical Diagnosis and Problem of the Developmental Delayed Child, The Journal of the Korean Association on Developmental Disabilities (2004), Vol.8, No.2, pp.81-96.

[8] H. Y. Kim and J. H. Lee, Experience on Health Care Needs of Mother with Developmental Disability Child, Nursing Science (2004), Vol.16, No.1, pp.44-50.

[9] T. H. Lee, Analysis of Variables Affecting Health Promotion Behavior, Thesis of Master, Yonsei University, Seoul, Korea (1989)

[10] J. E. Ware Jr., Scales for Measuring General Health Perceptions, Health Services Research (1976), Vol.11, No.4, pp.396-415.

[11] G. M. Wagnild and H. M. Young, Development and Psychometric, The Journal of Nursing Measurement (1993), Vol.1, No.2, pp.165-178.

[12] Y. S. Song, Determinants of Resilience of the Physically Disabled at Home, Thesis of Master, Kosin University, Busan, Korea (2004)

[13] R. R. Abidin, Parenting Stress index (PSI): Professional manual, Pediatric Psychology Press, New-York, USA (1990)

[14] K. S. Lee, K. M. Chung, J. A. Park, and H. J. Kim, Reliability and Validity Study for the Korean version of Parenting Stress index Short Form (K-PSI-SF), The Korean Journal of Woman Psychology (2008), Vol.13, No.3, pp363-377.

[15] R. M. Baron and D. A. Kenny, The Moderator-Mediator Variable Distinction in Social-psychological Research: Conceptual, Strategic, and Statistical Considerations, Journal of Personality and Social Psychology (1986), Vol.51, No.6, pp.1173-1182.

[16] P. Rhodes, Behavioral and Family Systems Interventions in Developmental Disability: towards a Contemporary and Integrative Approach, Journal of Intellectual \& Developmental Disability (2003), Vol.28, No.1, pp.51-64.

[17] K. B. Kyzar, A. P. Turnbull, J. A. Summers, and V. A. Gómez, The Relationship of Family Support to Family Outcomes: A Synthesis of Key Findings from Research on Severe Disability, Research \& Practice for Persons with Severe Disabilities (2012), Vol.37, No.1, pp.31-44.

[18] P. D. Mullen, D. G. Simons-Morton, G. Ramírez, R. F. Frankowski, L. W. Green, and D. A. Mains, A Meta-analysis of Trials Evaluating Patient Education and Counseling for Three groups of Preventive Health Behaviors, Patient education and counseling (1997), Vol.32, No.3, pp.157-173.

[19] K. S. Oh, Effects of a Social Support Group on Burden and Well-being of Mothers of Developmentally Delayed Children, Journal of Korean Academy of Nursing (1997), Vol.27, No.2, pp.389-400.

[20] K. H. Bae, Y. S. Chung, Effect of Social Support on the Quality of Life for Families of Young Children with Developmental Disabilities, Journal of Special Education \& Rehabilitation Science (2008), Vol.47, No.4, pp.115-137.

[21] H. Y. Kim, Development and Effect of Health Education Program for Mothers of Children with Developmental Disability. Proceedings of the 2nd International-Domestic Interdisciplinary Workshop, (2018) May 11-12; Jeju, Korea. 